P0109

\title{
A MEASUREMENT METHOD OF SPATIAL ILLUMINANCE DISTRIBUTION FOR AN OUTDOOR STADIUM MAKING USE OF A QUADCOPTER
}

Hirotaka SUZUKI et al.

DOI 10.25039/x46.2019.PO109

from

CIE x046:2019

Proceedings

of the

29th CIE SESSION

Washington D.C., USA, June 14 - 22, 2019

(DOI 10.25039/x46.2019)

The paper has been presented at the 29th CIE Session, Washington D.C., USA, June 14-22, 2019. It has not been peer-reviewed by CIE.

(C) CIE 2019

All rights reserved. Unless otherwise specified, no part of this publication may be reproduced or utilized in any form or by any means, electronic or mechanical, including photocopying and microfilm, without permission in writing from CIE Central Bureau at the address below. Any mention of organizations or products does not imply endorsement by the CIE.

This paper is made available open access for individual use. However, in all other cases all rights are reserved unless explicit permission is sought from and given by the CIE.

CIE Central Bureau

Babenbergerstrasse 9

A-1010 Vienna

Austria

Tel.: +4317143187

e-mail: ciecb@cie.co.at

www.cie.co.at 


\title{
A MEASUREMENT METHOD OF SPATIAL ILLUMINANCE DISTRIBUTION FOR AN OUTDOOR STADIUM MAKING USE OF A QUADCOPTER
}

\author{
Suzuki, H. ${ }^{1}$, Iwata, M. ${ }^{2}$, Akizuki, Y. ${ }^{3}$ \\ ${ }^{1}$ Kobe University, Kobe, JAPAN, ${ }^{2}$ Setsunan University, Neyagawa, JAPAN, ${ }^{3}$ University of \\ Toyama, Toyama, JAPAN \\ hirotakasuzuki@people.kobe-u.ac.jp
}

DOI 10.25039/x46.2019.PO109

\begin{abstract}
Understanding quality and quantity of lighting environment of the space especially for sports is quite significant. Sometimes, position and angle of lighting equipment in the space may be slightly different from designed position and angle. And the slight errors causes unexpected dark spot if the space is very large, and the dark spot may be significant problem at sports event. To prevent such problem, an illuminance distribution measurement method making use of quadcopter had been proposed. However, the accuracy of the method was validated with illuminance value measured at indoor space, and the position of quadcopter was determined according to the position of lighting equipment attached to ceiling of the indoor space. To extend the measurement method so that illuminance distribution at outdoor space can be obtained without position information of lighting equipment, authors proposed the measurement method making use of markers located on the ground of the space. To validate accuracy of proposed method, illuminance value measured by mobile operation with quadcopter and that by manual operation by hand were compared. And as a practical example, visibility of rugby ball at a stadium was simulated making good use of measured illuminance value at higher level by mobile operation.
\end{abstract}

Keywords: Quadcopter, Outdoor Stadium, Illuminance Distribution, Visibility

\section{Introduction}

Understanding quality and quantity of lighting environment of the space especially for sports is quite significant. Rapid development of lighting simulation technology in recent days enables precise prediction of lighting environment before construction of a building. However, at a constructing process, sometimes position and angle of lighting equipment in the space may be slightly different from designed position and angle. The slight error causes unexpected dark spot if the space is very large, and the dark spot may be significant problem if the space is used for sports like stadium (See Fig.1). To prevent such mistake, illuminance distribution in the space including higher space must be examined after completion of the building construction, though continuous measurement of illuminance in larger space is highly troublesome and measurement in higher space needs special device like high elevation work vehicle.

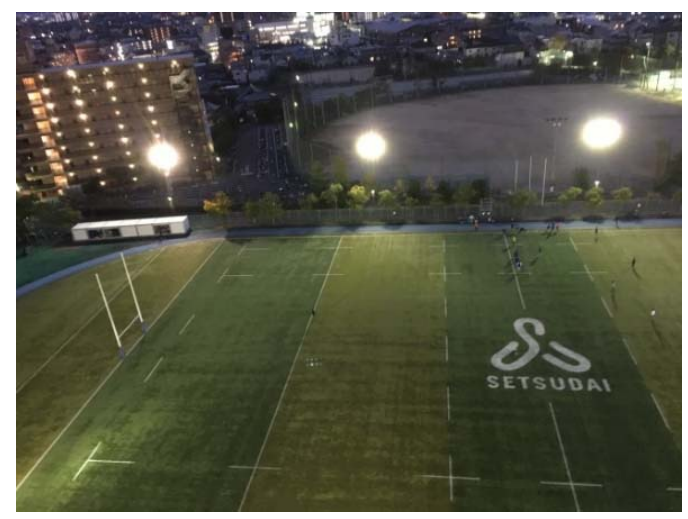

Figure 1 - An example of the space for sports (The first ground of Setsunan University) 
The objective of the research described in the paper is establishment of continuous and spatial measurement of lighting environment in large space for sports making use of quadcopter in order to understand differences between designed lighting environment and constructed lighting environment. Usually, illuminance distribution diagram is made from limited number of measured illuminance values at same height as shown in Fig. 2.

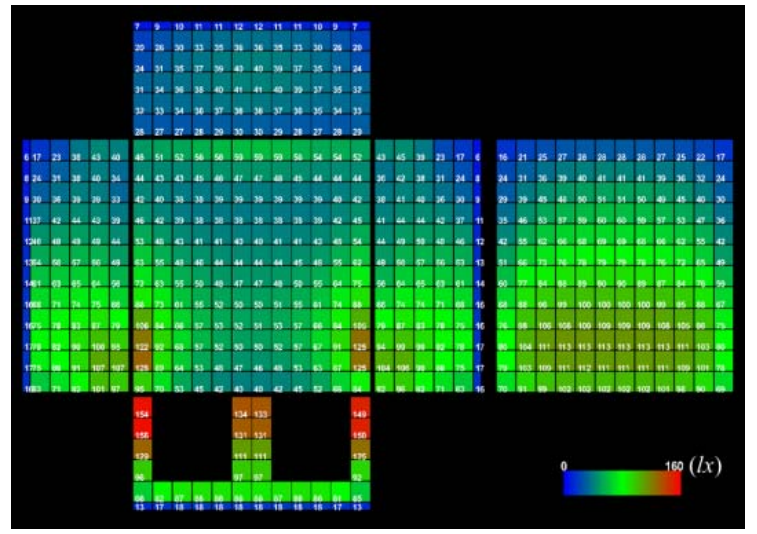

Figure 2 - An example of illuminance distribution representation

However, continuous and spatial measurement of lighting environment is essential for evaluation in a large stadium (See Fig.1). If a quadcopter is introduced in a process of illuminance measurement, the quadcopter can fly inside of a large space at each height and can obtain continuous illuminance values with attached illuminance meter. Quadcopter can fly every part of the space as shown in Fig. 3, and measure illuminance value continuously.

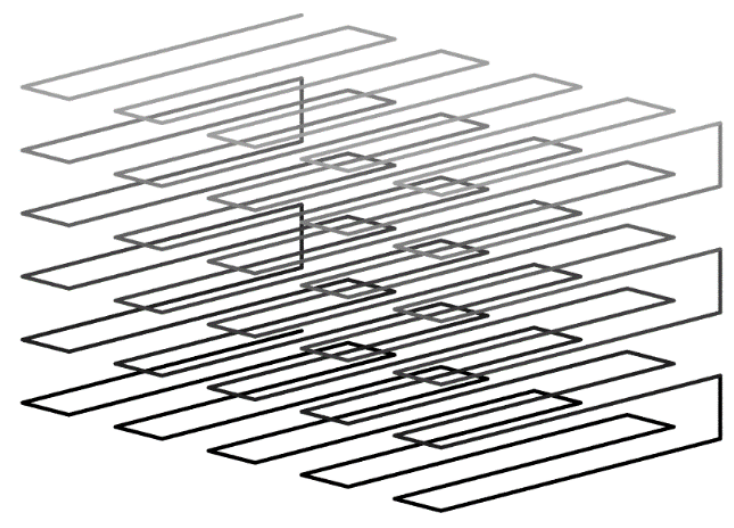

Figure 3 - An example of flying route for quadcopter

As for measurement by mobile operation making use of moving device, Nabeshima et al. (2006) had measured heat environment making use of automobile to understand distribution of air temperature at night time in Osaka plain, though the movement of the automobile was limited to horizontal direction. Yamada et al. (2016) had measured horizontal illuminance and vertical illuminance with quadcopter, though the quadcopter was hovering while measuring illuminance. Suzuki et al. (2017) and Maemura et al. (2017a) proposed illuminance measurement method making use of quadcopter and confirm accuracy of the method by making comparison between illuminance value by mobile operation with quadcopter and that by manual operation by hand, though the comparison was carried out with the value measured in indoor gymnasium. Maemura et al. (2017b) also pointed out that almost all ratios of vertical illuminance to horizontal illuminance in an existing gymnasium were out of allowance considering regulation of lighting for football described by CIE as shown in Fig. 4 .

Measurement by mobile operation in indoor gymnasium, positions of lighting equipment attached to ceiling can be used to determine position of quadcopter. However, when it comes 


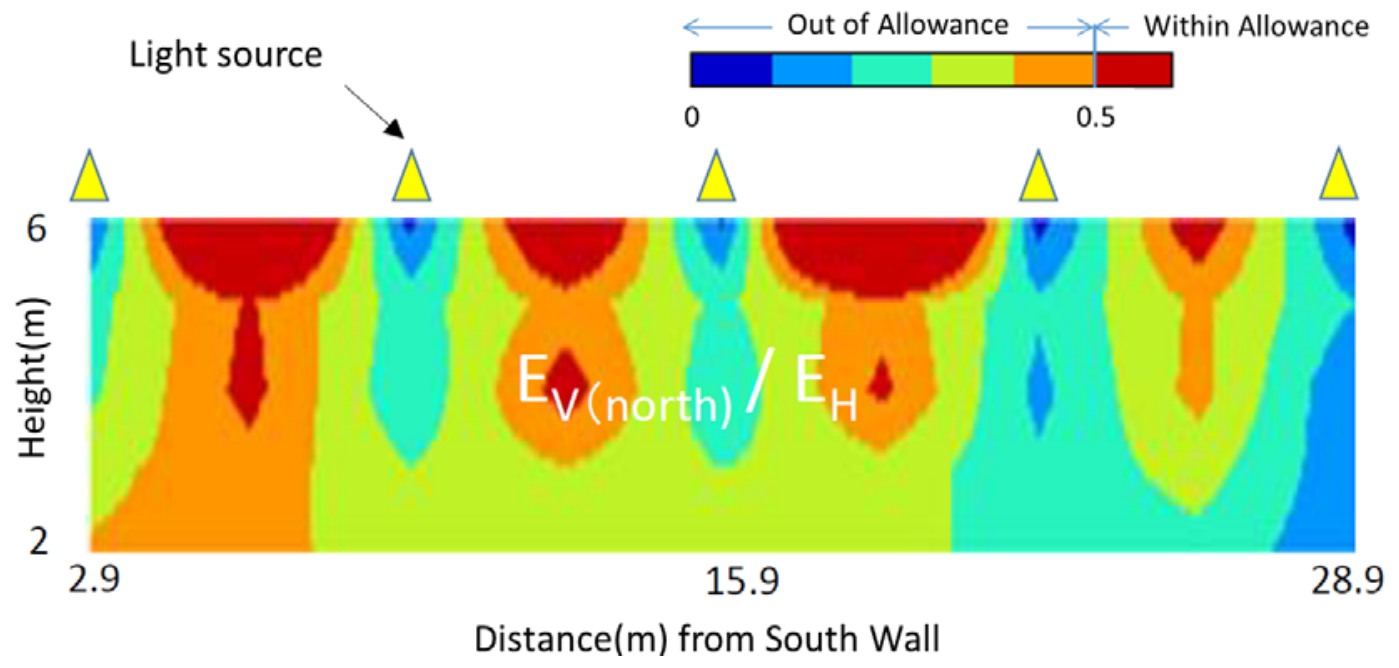

Figure 4 - Distribution of ratio of average value of vertical illuminance in four direction to horizontal illuminance (Maemura et al. 2017b)

to measurement in outdoor stadium, there is no ceiling and no lighting equipment attached to ceiling. To extend the measurement method so that illuminance distribution at outdoor space can be obtained without position information of lighting equipment, authors proposed the measurement method making use of markers located on the ground of the space. To validate accuracy of proposed method, illuminance value measured by mobile operation with quadcopter and that by manual operation by hand were compared. And as a practical example, visibility of rugby ball at the stadium was simulated making good use of measured illuminance value at higher level by mobile operation.

\section{Measurement of illuminance distribution by mobile operation with quadcopter}

Measurement of illuminance distribution by mobile operation with quadcopter was performed at the first ground of Setunan University (See Fig. 1). As shown in Fig. 5, a grid pattern (unit = $5 \mathrm{~m} \times 10 \mathrm{~m}$ ) was set at south east part of the ground taking into account symmetry condition. Eight halogen lamps were existing around the ground.

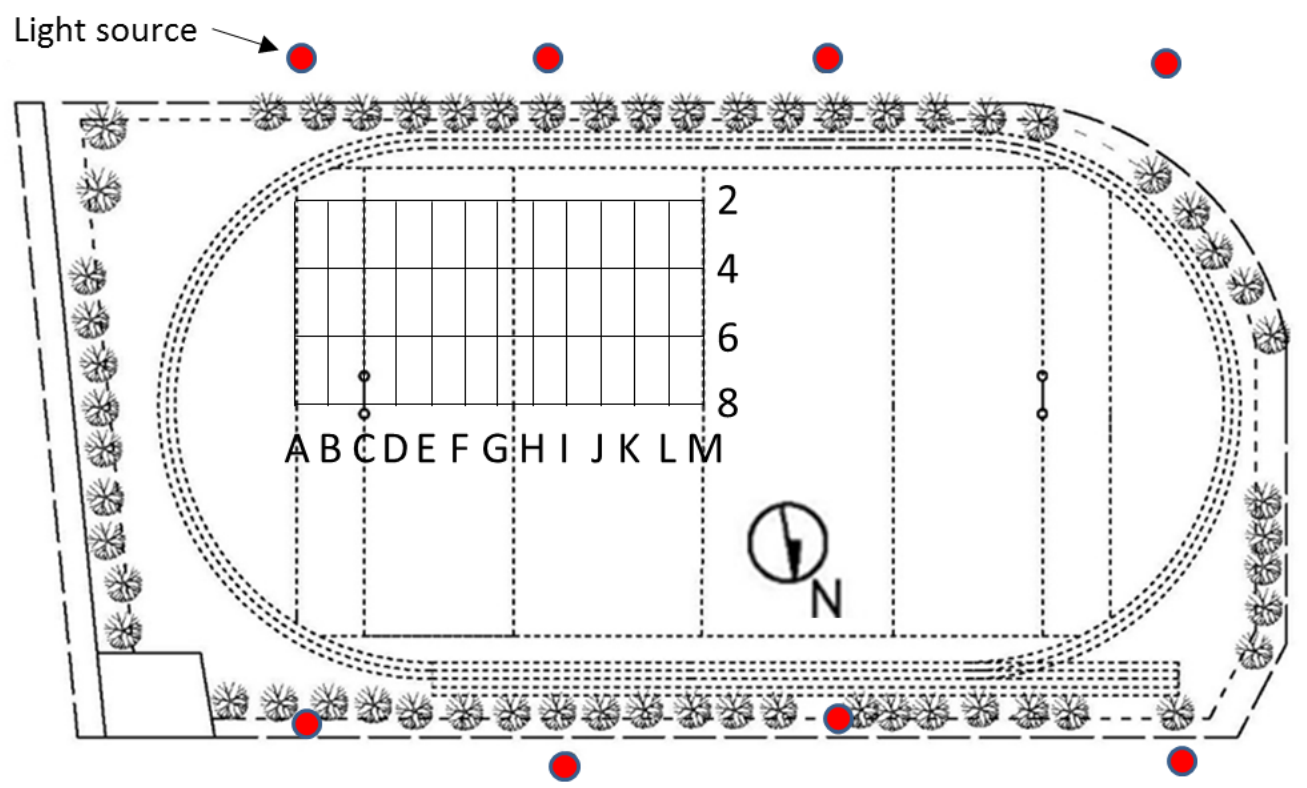

Figure $5-$ Grid pattern (unit $=5 \mathrm{~m} \times 10 \mathrm{~m}$ ) set at south east part of the first ground of Setsunan University 
Data loggers TR-74Ui (T\&D Corporation) with illuminance meter were attached into the quadcopter PHANTOM4 (DJI, Da-Jiang Innovations Science and Technology Co., Ltd.). And along with line 2 , line 4 , line 6 and line 8 , the quadcopter flew for measurement. The heights of measurement were $1 \mathrm{~m}$ and $2 \mathrm{~m}$. Red markers with the round shape (radius $=50 \mathrm{~mm}$ ) were located at the cross points on the grid shown in Fig. 5. Position of flying quadcopter was confirmed by location of the marker on the images taken by camera attached to the gimbal device on the quadcopter.

Upper horizontal illuminance, lower horizontal illuminance and vertical illuminances in four directions were measured. Fig. 6 shows measured horizontal illuminance (upper) distribution by mobile operation at the height $1 \mathrm{~m}$ and Fig. 7 shows vertical illuminance (east) distribution at the height $1 \mathrm{~m}$.

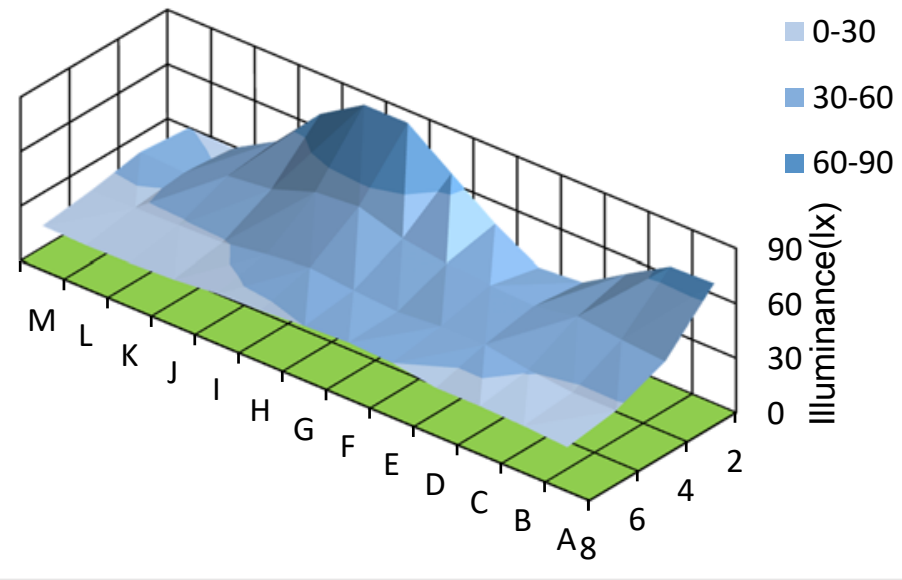

Figure 6 - Measured horizontal illuminance (upper) distribution at the height $1 \mathrm{~m}$

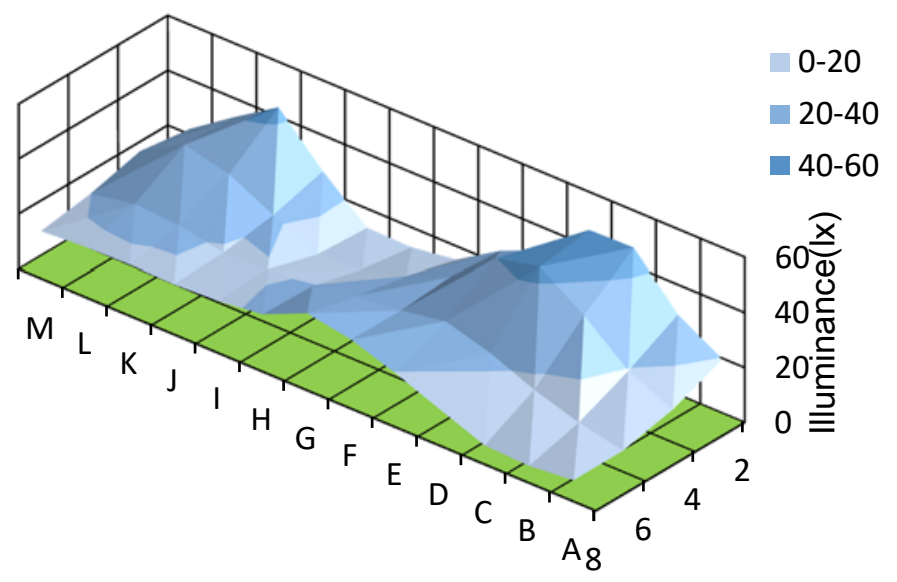

Figure 7 - Measured vertical illuminance (east) distribution at the height $1 \mathrm{~m}$

\section{Comparison of measured illuminance distribution by mobile operation with that by manual operation with hand}

To make sure the accuracy of illuminance distribution measured by mobile operation, measurement of illuminance distribution by manual operation with hand was performed at the cross points on the grid shown in Fig. 5 with luminance meter IM-5. Fig. 8 shows measured illuminance distribution by mobile operation and that by manual operation along with line 2 , line 4 , line 6 and line 8 . The values of illuminance measured by mobile operation and that by manual operation at the same point were approximately equal at almost all points as shown in the Fig. 8. And accuracy of the values of illuminance measured by mobile operation was confirmed by the comparison. 


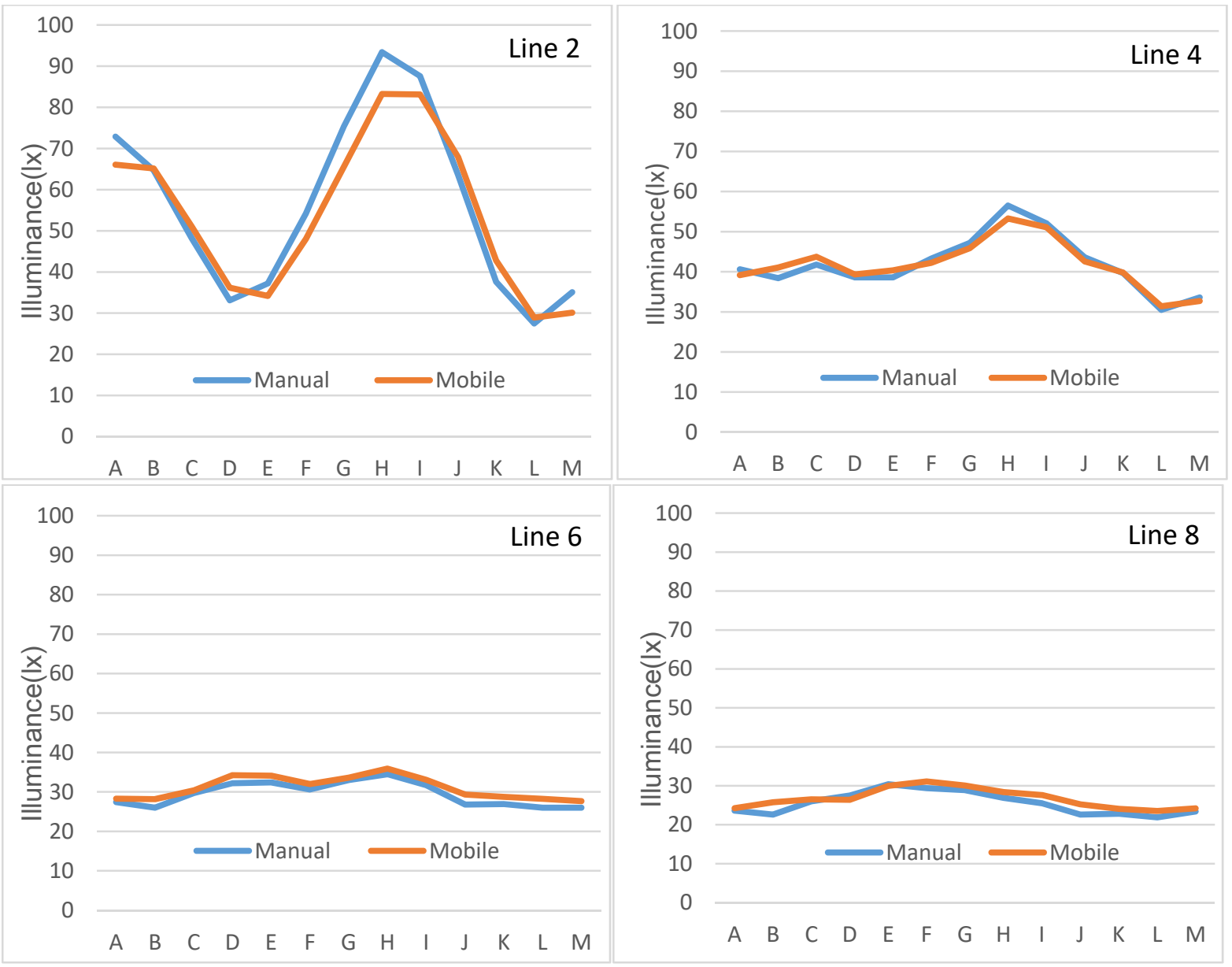

Figure 8 - Measured illuminance distribution by mobile operation and that by manual operation along with line 2, line 4, line 6 and line 8

\section{Simulation of visibility of rugby ball at the stadium}

As a practical example, visibility of rugby ball at a stadium was simulated making good use of measured illuminance value at higher level by mobile operation. From vertical illuminance values at the height $2 \mathrm{~m}$, luminace values of rugby ball were calculated. Fig. 9 shows luminance values of north side of rugby ball at the height $2 \mathrm{~m}$ calculated from the values of vertical illuminance of north direction and reflectance of rugby ball.

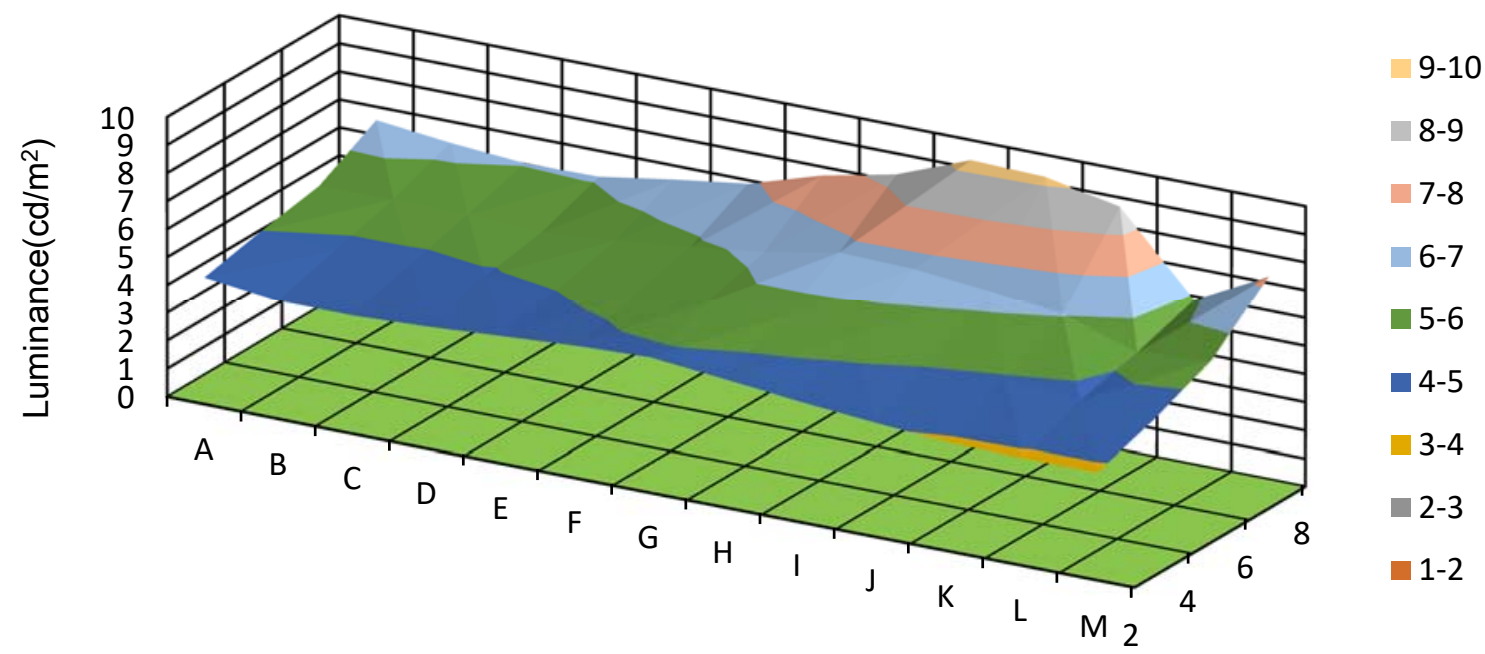

Figure 9 - Luminance values of north side of rugby ball 
And the values calculated were overlapped on measured luminance distribution at the ground. The luminance distribution was measured from the point M-8 on the grid as shown in Fig. 10. With the assumption that rugby ball was located on the line 6 , the luminance value of north side of rugby ball was calculated. From average of luminance values on the line 6 , the luminance value was calculated as $5.8\left(\mathrm{~cd} / \mathrm{m}^{2}\right)$. As the luminance value at lighting source was approximately $140\left(\mathrm{~cd} / \mathrm{m}^{2}\right)$ and the luminance value at the sky was approximately $0.5\left(\mathrm{~cd} / \mathrm{m}^{2}\right)$, luminance contrast of the rugby ball on the light source was 0.96 and that on the sky was 0.92 . From the study, it was confirmed that visibility of rugby ball on the light source and that on the sky were satisfactory on the ground with existing lighting equipment.

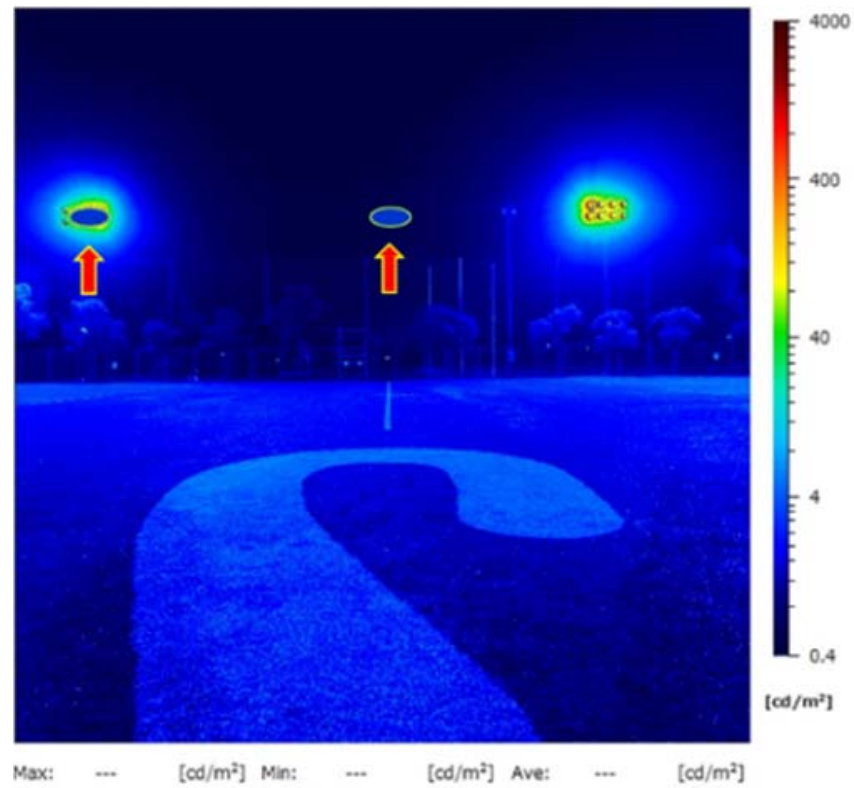

Figure 10 - Measured luminance distribution from the point M-8 and superimposed rugby balls on the light source and on the sky

(Red arrows are indicating the position of superimposed rugby balls)

\section{Conclusion and future works}

To extend measurement method of illuminance making good use of quadcopter so that illuminance distribution at outdoor space can be obtained without position information of lighting equipment, authors proposed the measurement method making use of markers located on the ground of the space. To validate accuracy of proposed method, illuminance value measured by mobile operation with quadcopter and that by manual operation by hand were compared. And as a practical example, visibility of rugby ball at a stadium was simulated making good use of measured illuminance value at higher level by mobile operation. Authors would like to introduce automatic operation of quadcopter to reduce the load of manipulator of quadcopter.

\section{Acknowledgement}

Authors would like to express the deepest appreciation to Mr. Kazunori Miura, a graduate of Setsunan University, who elaborately arranged the measured values and to staffs of JUAVAC Drone Expert Academy Hyogo who carefully controlled the quadcopter at the first ground of Setsunan University. 


\section{References}

MAEMURA, T., NAKURA, K., SUZUKI, H., AKIZUKI, Y., IWATA, M. and MATSUMOTO, N. 2017a. PRELIMINARY STUDY OF ILLUMINANCE DISTRIBUTION MEASUREMENT MAKING USE OF QUADCOPTER -EXAMINATION OF ACCURACY AND DRAWING OF ILLUMINANCE DISTRIBUTION. Proc. of the 11th Asian Forum on Graphic Science, \#F33, 7 pages in Conference USB Memory.

MAEMURA, T., NAKURA, K., SUZUKI, H., AKIZUKI, Y., IWATA, M. 2017b. Proposal of measurement method of illuminance distribution by mobile operation. -Part 2: Measurement of spatial illuminance distribution making use of quadcopter-. Proceeding of annual conference of the Illuminating Engineering Institute of Japan, 2 pages in Conference USB Memory

NABESHIMA, M., KOZAKI, Y., NAKAO, M. and NISHIOKA, M. 2006. EXPERIMENTAL STUDY OF HEAT ISLAND PHENOMINA BY MOBILE MEASUREMENT SYSTEM HOLIZONTAL AIR TEMPERATURE DISTRIDUTION AT NIGHT IN THE OSAKA PLAIN. Journal of Heat Island Institute International, 1, 23-29.

SUZUKI, H., NAKURA, K., MAEMURA, T., IWATA, M., AKIZUKI, Y. and MATSUMOTO, N. 2017. PRELIMINARY STUDY OF ILLUMINANCE DISTRIBUTION MEASUREMENT MAKING USE OF QUADCOPTER -STUDY OF GEOMETRICAL CONDITION. Proc. of the 11th Asian Forum on Graphic Science, \#F32, 6 pages in Conference USB Memory.

Yamada, T., Sugiyama, K., Muramatsu, J. and Kobashi, M. 2016. Consideration of the Required Spatial Illumination for Night Games. Summary of 2016 (49th) Annual Conference of The Illuminating Engineering Institute of Japan, 03-21. 